\title{
Statin and the Risk of Ischemic Stroke or Transient Ischemic Attack in Head and Neck Cancer Patients with Radiotherapy
}

\author{
Bo-Ching Lee, ${ }^{\mathrm{a}}$ Cheng-Li Lin, ${ }^{\mathrm{b}}$ Hsin-Hsi Tsai, ${ }^{\mathrm{c}}$ Chia-Hung Kao ${ }^{\mathrm{d}, \mathrm{e}, \mathrm{f}}$ \\ aDepartment of Medical Imaging, National Taiwan University Hospital, Taipei, Taiwan \\ ${ }^{b}$ Management Office for Health Data, China Medical University Hospital, Taichung, Taiwan \\ 'Department of Neurology, National Taiwan University Hospital Bei-Hu Branch, Taipei, Taiwan \\ ${ }^{d}$ Department of Nuclear Medicine and PET Center, China Medical University Hospital, Taichung, Taiwan \\ 'Graduate Institute of Biomedical Sciences and School of Medicine, College of Medicine, China Medical University, Taichung, Taiwan \\ fDepartment of Bioinformatics and Medical Engineering, Asia University, Taichung, Taiwan
}

\section{Dear Sir:}

We read with great interest the study entitled "Incidental statin use and the risk of stroke or transient ischemic attack after radiotherapy for head and neck cancer" by Addison et al. ${ }^{1}$ The study, which included 1,011 head and neck cancer (HNC) patients with $288(28 \%)$ on statins, found that statin was protective against the development of transient ischemic attack (TIA) and ischemic stroke after radiotherapy during a median followup of 3.4 years.

With the aim to examine the association between statin and stroke risk after radiotherapy in a larger cohort of HNC patients, we conducted a nationwide population-based study using data from the National Health Insurance Research Database. International Classification of Diseases, Ninth Revision, Clinical Modification was used for disease identification and the cancer status was confirmed using the catastrophic illness registry. We identified newly diagnosed HNC patients receiving radiotherapy from January 1, 2000 to December 31, $2010(n=48,548)$, and patients with previous cancer or radiotherapy history were excluded for further analysis. Statin user was defined as use of statin during the entire course of radiotherapy. After propensity score matching of the selected comorbidities, there were 1,073 patients receiving statin (user group) and 1,073 matched patient not receiving statin (nonuser group) during radiotherapy and followup. The demographics were not different between the user and nonuser groups except for the use of antithrombotics and anti- hypertensives, which were of higher incidence in the user group (Table 1). In total, TIA or ischemic stroke developed in 64 patients in the user group and 45 in the nonuser group during the study period, respectively. Cumulative incidences of developing TIA or ischemic stroke in the user and nonuser groups were presented in Figure 1, and no significant difference was observed (log-rank test, $P=0.29$ ). The risk of TIA or ischemic stroke was also similar in the competing-risk regression model (adjusted subhazard ratio, 1.35; 95\% confidence level, 0.95 to 1.91). Further subgroup analysis showed that statin was associated with reduced risk of TIA or ischemic stroke in patient over 65 years of age, but with elevated risk of TIA or ischemic stroke in female patients (Supplementary Table 1). We also found no significant difference between different statins on the TIA or ischemic stroke incidence.

The preliminary findings from this study showed that the legacy effect of statin during radiotherapy does not lower the subsequent risk of TIA and ischemic stroke in patient with HNC, which is contradictory to the report by Addison et al. ${ }^{1}$ Our study population, which comprised mostly of Asians, was different from that of Addison's, and the different ethnic background may contribute to divergent statin resistance. Moreover, nasopharyngeal carcinoma consisted of a significant proportion of HNC in Taiwan. ${ }^{2}$ The different treatment field in radiotherapy for HNC may result in different carotid artery pathology. The large sample size and wide coverage (>99\%) of the National Health Insurance are the strong points of this study, while the study limi- 
Table 1. Comparisons in demographic characteristics and comorbidities in head and neck cancer patient with and without statin during radiotherapy

\begin{tabular}{|c|c|c|c|}
\hline \multirow{2}{*}{ Characteristic } & \multicolumn{2}{|c|}{ Statin } & \multirow{2}{*}{$P$} \\
\hline & No $(n=1,073)$ & Yes $(n=1,073)$ & \\
\hline Gender & & & 0.21 \\
\hline Women & $124(11.6)$ & $143(13.3)$ & \\
\hline Men & $949(88.4)$ & $930(86.7)$ & \\
\hline Age stratified (yr) & & & 0.69 \\
\hline$\leq 49$ & 149 (13.9) & $163(15.2)$ & \\
\hline $50-64$ & $549(51.2)$ & $539(50.2)$ & \\
\hline$\geq 65$ & $375(35.0)$ & $371(34.6)$ & \\
\hline Age $(y r)^{*}$ & $60.5 \pm 10.2$ & $60.6 \pm 10.5$ & 0.90 \\
\hline \multicolumn{4}{|l|}{ Comorbidity } \\
\hline Hypertension & 840 (78.3) & $830(77.4)$ & 0.60 \\
\hline Hyperlipidemia & $882(82.2)$ & $882(82.2)$ & 0.99 \\
\hline Diabetes & $531(49.5)$ & $524(48.8)$ & 0.76 \\
\hline Congestive heart failure & $102(9.5)$ & $123(11.5)$ & 0.14 \\
\hline Hypercoagulability & $4(0.4)$ & $4(0.4)$ & 0.99 \\
\hline Atrial fibrillation & $19(1.8)$ & $25(2.3)$ & 0.36 \\
\hline Coronary artery disease & $449(41.9)$ & $467(43.5)$ & 0.43 \\
\hline Chronic kidney disease and ESRD & $170(15.8)$ & $181(16.9)$ & 0.52 \\
\hline Previous stroke & $175(16.3)$ & $180(16.8)$ & 0.77 \\
\hline \multicolumn{4}{|l|}{ Medication } \\
\hline Aspirin & $891(83.0)$ & $937(87.3)$ & 0.01 \\
\hline Clopidogrel & $89(8.3)$ & $248(23.1)$ & $<0.01$ \\
\hline ACEI & $627(58.4)$ & 706 (65.8) & $<0.01$ \\
\hline ARB & $463(43.2)$ & 604 (56.3) & $<0.01$ \\
\hline Warfarin & $42(3.9)$ & $61(5.7)$ & 0.06 \\
\hline \multicolumn{4}{|l|}{ Treatment } \\
\hline Surgery & 181 (16.9) & $182(17.0)$ & 0.95 \\
\hline Chemotherapy & 776 (72.3) & 765 (71.3) & 0.60 \\
\hline Cetuximab & $18(1.7)$ & $25(2.3)$ & 0.28 \\
\hline
\end{tabular}

Values are presented as number $(\%)$ or mean \pm SD. Chi-square test. ESRD, end-stage renal disease; ACEl, angiotensin-converting-enzyme inhibitor; ARB, angiotensin II receptor blocker.

*t-test.

tation is the potential insufficient adjustments for the various confounding factors from its retrospective design.

In summary, statin use during radiotherapy was not associated with reduced risk of TIA or ischemic stroke in Taiwanese patients with HNC. Possible difference in statin resistance and types of HNC might be the explanation for the inconsistent result with the previous study. Future large-scale prospective studies are necessary to determine effectiveness of statin in preventing radiation-induced vascular disease and stroke.

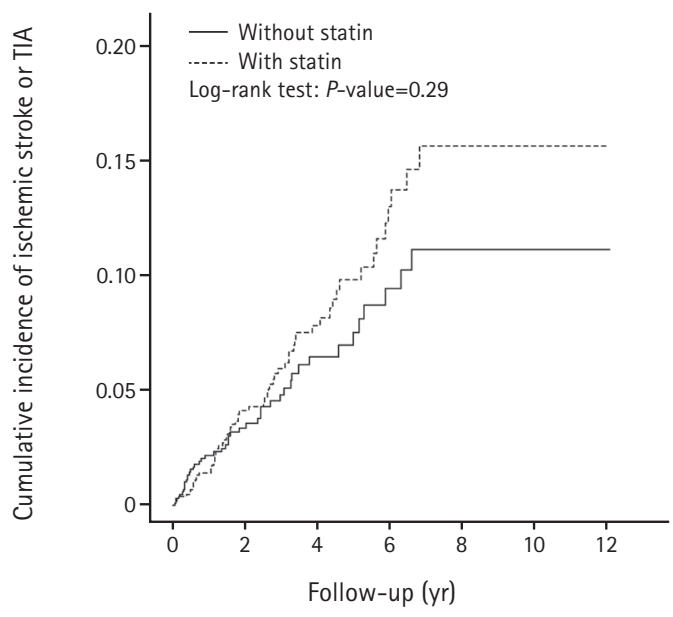

Figure 1. Cumulative incidence of ischemic stroke or transient ischemic attack (TIA) in the user and nonuser group during follow-up.

\section{Supplementary materials}

Supplementary materials related to this article can be found online at https://doi.org/10.5853/jos.2018.01585.

\section{References}

1. Addison D, Lawler PR, Emami H, Janjua SA, Staziaki PV, Hallett TR, et al. Incidental statin use and the risk of stroke or transient ischemic attack after radiotherapy for head and neck cancer. J Stroke 2018;20:71-79.

2. Chiang CJ, Lo WC, Yang YW, You SL, Chen CJ, Lai MS. Incidence and survival of adult cancer patients in Taiwan, 20022012. J Formos Med Assoc 2016;115:1076-1088.

Correspondence: Chia-Hung Kao

Graduate Institute of Biomedical Sciences and School of Medicine, College of Medicine, China Medical University, No. 2, Yuh-Der Rd, Taichung 40447,

Taiwan

Tel: +886-4-2205-2121

Fax: +886-4-2233-6174

E-mail:d10040@mail.cmuh.org.tw

Received: May 31, 2018

Revised: August 5, 2018

Accepted: August 10, 2018

This work was supported by grants from the Ministry of Health and Welfare, Taiwan (MOHW107-TDU-B-212-123004); China Medical University Hospital (DMR-107-192); Academia Sinica Stroke Biosignature Project (BM10701010021); MOST Clinical Trial Consortium for Stroke (MOST 106-2321-B-039-005-); TsengLien Lin Foundation, Taichung, Taiwan; and Katsuzo and Kiyo Aoshima Memorial Funds, Japan. The funders had no role in study design, data collection and analysis, decision to publish, or preparation of the manuscript. No additional external funding received for this study.

The authors have no financial conflicts of interest. 
Supplementary Table 1. Incidences and subhazard ratios of ischemic stroke or TIA in head and neck cancer patient with and without statin during radiotherapy stratified by demographics and comorbidity in the competing-risk regression model

\begin{tabular}{|c|c|c|c|c|c|c|c|c|}
\hline \multirow{3}{*}{ Ischemic stroke or TIA } & \multicolumn{6}{|c|}{ Statin } & \multirow{3}{*}{$\begin{array}{l}\text { Crude SHR } \\
(95 \% \mathrm{Cl})\end{array}$} & \multirow{3}{*}{$\begin{array}{l}\text { Adjusted SHR } \\
\quad(95 \% \mathrm{Cl})\end{array}$} \\
\hline & \multicolumn{3}{|c|}{ No } & \multicolumn{3}{|c|}{ Yes } & & \\
\hline & Event & PY & Rate $^{*}$ & Event & PY & Rate $^{*}$ & & \\
\hline Overall & 45 & 2,708 & 16.6 & 64 & 3,090 & 20.7 & $1.45(1.04-2.00)^{7}$ & $1.35(0.95-1.91)$ \\
\hline \multicolumn{9}{|l|}{ Age group (yr) } \\
\hline$\leq 49$ & 4 & 444 & 9.00 & 9 & 511 & 17.6 & $1.12(0.70-1.80)$ & $1.15(0.67-1.95)$ \\
\hline $50-64$ & 23 & 1,430 & 16.1 & 25 & 1,550 & 16.1 & $0.77(0.62-0.97)^{+}$ & $0.83(0.65-1.05)$ \\
\hline$\geq 65$ & 18 & 834 & 21.6 & 30 & 1,028 & 29.2 & $0.69(0.53-0.91)^{5}$ & $0.74(0.56-0.99)^{\dagger}$ \\
\hline$P$ for interaction & & & & & & & & 0.87 \\
\hline \multicolumn{9}{|l|}{ Gender } \\
\hline Women & 3 & 371 & 8.08 & 9 & 453 & 19.9 & $4.37(0.70-27.5)$ & $4.19(1.03-17.0)^{\dagger}$ \\
\hline Men & 42 & 2,337 & 18.0 & 55 & 2,636 & 20.9 & $1.15(0.80-1.65)$ & $1.02(0.69-1.52)$ \\
\hline$P$ for interaction & & & & & & & & 0.24 \\
\hline \multicolumn{9}{|l|}{ Comorbidity } \\
\hline No & 0 & 44 & 0.00 & 1 & 52 & 19.3 & - & - \\
\hline Yes & 45 & 2,664 & 16.9 & 63 & 3,038 & 20.7 & $1.23(0.86-1.76)$ & $1.09(0.74-1.61)$ \\
\hline$P$ for interaction & & & & & & & & $<0.001$ \\
\hline \multicolumn{9}{|l|}{ Medication } \\
\hline \multicolumn{9}{|l|}{ Aspirin } \\
\hline No & 4 & 413 & 9.68 & 3 & 345 & 8.69 & - & - \\
\hline Yes & 41 & 2,295 & 17.9 & 61 & 2,744 & 22.2 & $1.17(0.80-1.71)$ & $1.10(0.74-1.64)$ \\
\hline$P$ for interaction & & & & & & & & 0.28 \\
\hline \multicolumn{9}{|l|}{ Clopidogrel } \\
\hline No & 42 & 2,497 & 16.8 & 50 & 2,370 & 21.1 & $1.17(0.79-1.74)$ & $1.00(0.63-1.57)$ \\
\hline Yes & 3 & 211 & 14.2 & 14 & 719 & 19.5 & $2.00(0.56-7.09)$ & $3.85(0.36-41.7)$ \\
\hline$P$ for interaction & & & & & & & & 0.26 \\
\hline \multicolumn{9}{|l|}{ ACEI } \\
\hline No & 11 & 1,171 & 9.39 & 15 & 1,090 & 13.8 & $2.07(0.71-6.03)$ & $1.53(0.46-5.07)$ \\
\hline Yes & 34 & 1,537 & 22.1 & 49 & 1,999 & 24.5 & $1.13(0.74-1.74)$ & $1.10(0.70-1.71)$ \\
\hline$P$ for interaction & & & & & & & & 0.26 \\
\hline \multicolumn{9}{|l|}{ ARB } \\
\hline No & 22 & 1,469 & 15.0 & 34 & 1,276 & 26.7 & $2.16(1.09-4.28)^{\dagger}$ & $1.89(0.92-3.89)$ \\
\hline Yes & 23 & 1,239 & 18.6 & 30 & 1,814 & 16.5 & $0.93(0.51-1.70)$ & $0.74(0.36-1.51)$ \\
\hline$P$ for interaction & & & & & & & & 0.36 \\
\hline \multicolumn{9}{|l|}{ Warfarin } \\
\hline No & 44 & 2,607 & 16.9 & 61 & 2,879 & 21.2 & $1.45(1.00-2.09)^{\dagger}$ & $1.31(0.88-1.94)$ \\
\hline Yes & 1 & 101 & 9.92 & 3 & 210 & 14.3 & - & - \\
\hline$P$ for interaction & & & & & & & & 0.10 \\
\hline \multicolumn{9}{|l|}{ Treatment } \\
\hline Surgery & 37 & 2,187 & 16.9 & 56 & 2,513 & 22.3 & $1.34(0.90-1.99)$ & $1.32(0.86-2.01)$ \\
\hline No & 8 & 521 & 15.3 & 8 & 577 & 13.9 & $0.81(0.23-2.91)$ & $0.85(0.27-2.61)$ \\
\hline Yes & & & & & & & & 0.23 \\
\hline \multicolumn{9}{|l|}{$P$ for interaction } \\
\hline \multicolumn{9}{|l|}{ Chemotherapy } \\
\hline No & 9 & 853 & 10.6 & 24 & 1,031 & 23.3 & $2.53(0.99-6.44)$ & $2.05(0.74-5.69)$ \\
\hline
\end{tabular}


Supplementary Table 1. Continued

\begin{tabular}{|c|c|c|c|c|c|c|c|c|}
\hline \multirow{3}{*}{ Ischemic stroke or TIA } & \multicolumn{6}{|c|}{ Statin } & \multirow{3}{*}{$\begin{array}{l}\text { Crude SHR } \\
(95 \% \mathrm{Cl})\end{array}$} & \multirow{3}{*}{$\begin{array}{l}\text { Adjusted SHR }{ }^{+} \\
\quad(95 \% \mathrm{Cl})\end{array}$} \\
\hline & \multicolumn{3}{|c|}{ No } & \multicolumn{3}{|c|}{ Yes } & & \\
\hline & Event & PY & Rate $^{*}$ & Event & PY & Rate $^{*}$ & & \\
\hline Yes & 36 & 1,855 & 19.4 & 40 & 2,059 & 19.4 & $1.11(0.69-1.77)$ & $1.03(0.58-1.84)$ \\
\hline$P$ for interaction & & & & & & & & 0.12 \\
\hline \multicolumn{9}{|l|}{ Cetuximab } \\
\hline No & 45 & 2,689 & 16.7 & 64 & 3,042 & 21.0 & $1.27(0.89-1.81)$ & $1.13(0.76-1.67)$ \\
\hline Yes & 0 & 19 & 0.00 & 0 & 47 & 0.00 & - & - \\
\hline$P$ for interaction & & & & & & & & 0.82 \\
\hline
\end{tabular}

TIA, transient ischemic attack; PY, person-year; SHR, subhazard ratio; $\mathrm{Cl}$, confidence interval; $\mathrm{ACEl}$, angiotensin-converting-enzyme inhibitor; $\mathrm{ARB}$, angiotensin II receptor blocker.

*Incidence rate per 1,000 person-years; ${ }^{\dagger}$ Variable found to be significant in the Table 1 were further examined in the multivariable analysis (use of aspirin, clopidogrel, ACEI, and ARB); ${ }^{\ddagger} P<0.05 ;{ }^{\circledR} P<0.01$. 